\title{
PERANCANGAN SISTEM INFORMASI PENGELOLAAN SURAT MASUK SURAT KELUAR DAN SPPD DIKELURAHAN JATIJAJAR
}

\author{
Ari Susanto ${ }^{1}$, Ni Wayan Parwati ${ }^{2}$, Mei Lestari ${ }^{3}$ \\ Program Studi Teknik Informatika, Fakultas Teknik dan Ilmu Komputer, \\ Universitas Indraprasta PGRI \\ Jalan Raya Tengah No 80, Kelurahan Gedong, Pasar Rebo, Jakarta Timur \\ Susantoari26@gmail.com ${ }^{1}$,wayan.parwati@gmail.com ${ }^{2}$, mei.lestari6@gmail.com ${ }^{3}$
}

\begin{abstract}
Abstrak
Kelurahan merupakan tempat dimana kerja seorang lurah sebagai perangkat daerah kabupaten atau kota serta unit pemerintahan terkecil setingkat dengan desa. Kegiatan yang sering dilakukan di Kelurahan Jatijajar yaitu membuat surat masuk, surat keluar dan SPPD yang ada di bagian keuangan, baik umum maupun logistik. Kegiatan surat menyurat sangat penting dalam sebuah instansi pemerintah. Dalam pencatatan surat sering terjadi human error yang karena masih dilakukan secara manual, dan sulitnya pengecekan surat karena media pencatatan yang digunakan masih memakai media kertas. Sehingga, perlu adanya suatu sistem berupa aplikasi pengolahan surat, aplikasi ini dibuat untuk membantu kinerja pegawai dalam hal surat menyurat sehingga tidak banyak buku yang dikeluarkan untuk pencatatan sehingga dapat membantu dalam membuat laporan yang tepat dan akurat serta membantu mengendalikan proses pengolahan data surat di Keluarahan Jatijjar. Metode penelitian yang digunakan yaitu metode Grounded Research. Suatu metode penelitian yang berdasarkan pada fakta dan menggunakan analisis perbandingan dengan tujuan mengadakan generalisasi empiris, menetapkan konsep, membuktikan teori, mengembangkan teori, pengumpulan dan analisis data dalam waktu yang bersamaan. Tujuan dengan adanya aplikasi ini nantinya akan memudahkan dalam pengolahan data pembuatan laporan.
\end{abstract}

Kata Kunci: Sistem Informasi, Pengelolaan Surat, Kelurahan

\begin{abstract}
Kelurahan is the workplace of a lurah as a device of the district or city as well as the smallest government unit at the village level.. Activities that are often carried out in kelurahan Jatijajar are making incoming letters, outgoing letters and SPPD in the finance department, both general and logistics. Correspondence activities are very important in a government agency. In the recording of letters there is often a human error because it is still done manually, and the difficulty of checking the letter because the recording media used is still using paper media. So, there needs to be a system in the form of mail processing applications, this application is made to help the performance of employees in terms of correspondence so that not many books are issued for recording so that it can help in making accurate and accurate reports and help control the processing of mail data in kelurahan Jatijajar. The research method used is Grounded Research method. A method of research based on facts and using comparative analysis with the aim of conducting empirical generalizations, establishing concepts, proving theories, disseminating theories, collecting and analyzing data at the same time. The purpose with this application will be to facilitate the processing of report creation data.
\end{abstract}

Keywords: Information Systems, Letter Management, Village Office

\section{PENDAHULUAN}

Merambahnya Teknologi dan Informasi belakangan ini berpengaruh pada sendi - sendi kehidupan masyarakat. Banyak yang menginginkan perubahan-perubahan di setiap segi, yang salah satunya perubahan di bidang teknologi, ekonomi, sosial dan pendidikan. Kenyataan yang harus dihadapi dalam melakukan perubahan tersebut tidak lepas dari suatu permasalahan yang mendesak dan segera diselesaikan seefektif dan seefisien mungkin demi tercapainya cita-cita dari instansi atau organisasi tersebut. Menurut (Abdul, 2014) Sistem informasi adalah sebuah rangkaian prosedur formal dimana data dikelompokkan, diproses menjadi informasi, dan didistribusikan kepada pemakai. Kegiatan yang sering terjadi di Kelurahan Jatijajar yaitu mengenai surat yang masuk dan keluar hingga perjalanan dinas yang ada di Bagian Keuangan, Umum dan Logistik. Kegiatan surat menyurat sangat lah penting dalam sebuah instansi khusunya instansi pemerintah. Melihat 
kebutuhan dan situasi Kelurahan Jatijajar efektifitas pencatatan pendataan surat masuk, keluar dan sppd masih dilakukan secara manual dan penyimpaan yang masih di buku registernya. Sehingga, perlu adanya suatu Sistem Aplikasi Surat Masuk, Surat Keluar dan Sppd ini dibuat guna membantu kinerja staff keluarahan dalam hal mengelolah surat sehingga tidak banyak buku yang dikeluarkannya untuk pencatatan sehingga dapat membantu dalam membuat laporan yang tepat dan akurat serta untuk membantu mengendalikan proses surat menyurat Keluarah Jatijajar. Bedasarkan latar belakang di atas, maka peneliti memberikan solusi kendala-kendala pada proses pengolahan data surat masuk, keluar dan sppd, merancang sistem informasi pengelolaan surat yang dapat membantu proses pengarsipan, pencarian, dan apakah komputerisasi data penyelenggaraan dapat meningkatkan efisiensi waktu terhadap pengelolaan surat, membuat suatu sistem informasi pengelolaan surat yang dapat digunakan untuk mempercepat proses pengelolaan surat dan meningkatkan kinerja karyawan dan proses pengelolaan surat pada Kelurahan Jatijajar Kecamatan Tapos Kota Depok. Tujuan penelitian ini berdasarkan permasalahan diatas, , maka peneliti mendapatkan gambaran tentang sistem yang sedang berjalan dan mengetahui masalah yang dihadapi sebagai acuan pembuat sistem yang lebih efektif dan efisien, mengurangi masalah human error dalam mengolah data surat masuk, keluar dan sppd, serta pembuatan laporan sehingga dapat meningkatkan akurasi data , memberikan suatu solusi dengan merancang sebuah sistem aplikasi surat masuk, surat keluar dan sppd Kelurahan Jatijajar agar mudah dalam menganalisa, merancang dan mengimplementasikan sistem informasi pengelolaan surat terhadap proses pengarsipan. sehingga memudahkan karyawan dalam mengolah data aula. Penelitian ini diharapkan memberi manfaat bagi Kelurahan Jatijajar dalam mendapatkan sistem baru yang lebih efektif dan dapat memudahkan mengolah data-data yang dibutuhkan dengan cepat dan akurat dan memudahkan staff Kelurahan Jatijajar dalam mencatat serta mencari data surat masuk, surat keluar dan sppd.

\section{PENELITIAN RELEVAN}

Dalam rangka mendapatkan hasil penelitian yang baik, selain melakukan penelitian secara langsung peneliti juga melakukan kajian pustaka. Dari hasil penelitian yang telah dilakukan. Beberapa hasil acuan yang menjadi acuan adalah:

Penelitian dari (Fatmawati, Ferryanto, 2018) yang berjudul "Perancangan Sistem Informasi Pengolahan Data dan Pengarsipan Menggunakan Model Waterfall". Dengan adanya penelitian ini aplikasi pengolahan data dan pengarsipan dapat memudahkan pelanggan dalam memperoleh informasi mengenai produk yang ditawarkan oleh PT Dinamika Persada Makmur dalam meningkatkan pelayanan kepada pelanggan di berbagai wilayah baik dalam kota maupun luar kota, dan memudahkan bagian marketing pada PT. Dinamika Persada Makmur dalam menghemat waktu dan tempat menyimpan data.

Penelitian dari (Muhamad Rizqi Aris Munandar, 2020) yang berjudul "Perancangan Sistem Informasi Pengelolaan Arsip Pada Balai Bendungan Dirjen SDA Kementerian PUPR". Penelitian ini menghasilkan bagaimana prosese pendataan karyawan, prndataan rekanan, pendataan surat masuk dan keluar dapat dilakukan secra cepat dengan pengelolaan arsip yang benar. Untuk menyelesaikan laporan pengelolaan arsip harus dengan cepat, tepat, dan akurat, peranan komputer mutlak diperlukan. Hal ini dikarenakan kemampuan komputer yang dapat membantu menyelesaikan pekerjaan secara lebih cepat, tepat, dan akurat.

Penelitian dari (Adhi Susano, Pujiastuti, 2017) yang berjudul "Perancangan Aplikasi Pengolahan Data Administrasi Penduduk Pada Rukun Tetangga Wilayah Kreo Tangerang". Dengan adanya aplikasi ini tiap-tiap RT akan dapat lebih efesien dalam pencarian data warganya serta dapat lebih efektif dalam melayanin warganya dalan surat menyurat dan pendataan warga yang ekonominya mampu maupun yang tidak mampu. Hal ini nantinya akan mempermudah pekerjaan petugas sekretariat RW, meningkatkan keterampilan penggunaan teknologi bagi staff rukun tetangga dan dihasilkan data yang lengkap serta pelaporan yang tepat waktu. Selain itu merangsang tiap-tiap RT untuk melakukan inovasi-inovasi yang bermanfaat bagi masyarakat.

Penelitian dari (Hassan Saputra, 2020) yang berjudul "Rancang Bangun Sistem Distribusi Surat Kabar Pada PT Jasatama Polamedia Berbasis Web". Dengan adanya penelitian bahwa Sistem yang berjalan manual berubah menjadi sistem komputerisasi dengan menggunakan basis data dalam mempermudah karyawan untuk melakukan pengarsipan dokumen menjadi efektif, efisien dan 
akurat serta pembuatan inputan data pekerjaan menjadi cepat. Karena berbasis Web, sistem mampu melakukan pencarian data pelanggan, alamat pelanggan, telepon pelanggan, dan bisa mengetahui siapa yang mengirimkan surat kabar untuk pelanggan tersebut.

Penelitian dari (Ahmad Khoiril Anam, Hilda Hilaliyah, 2018) yang berjudul "Penulisan Surat Resmi Di Ikatan Remaja Masjid Kelurahan Jatiluhur Dan Jatimekar Kecamatan Jatiasih Kota Bekasi”. Konflik yang terjadi dewasa ini menyebabkan eksistensi organisasi masyarakat berbau keagamaan semakin tersudutkan. Padahal, hak dan kebebasan berorganisasi dilindungi oleh Undang-Undang Nomor 17 Tahun 2013 tentang Organisasi Masyarakat, termasuk organisasi keagamaan seperti ini. Salah satu upaya mempertahankan eksistensi organisasi semacam ini, tim pelaksana bermaksud mengadakan penyuluhan kebahasaan kepada beberapa ikatan remaja masjid yang kini masih bertahan. Selain itu, kegiatan ini bertujuan untuk memberikan pemahaman dan pelatihan tentang cara menulis surat resmi, membahas kesalahan-kesalahan yang sering muncul dalam penulisan surat.

\section{METODE PENELITIAN}

Menurut (Supriyati, 2012) metode penelitian adalah tatacara bagaimana suatu penelitian dilaksanakan. Metode penelitian yang digunakan untuk melakukan penelitian adalah metode grounded (grounded research). Menurut (Sugiyono, 2013) Metode Grounded Research yaitu suatu metode penelitian yang berdasarkan generasi empiris, menetapkan konsep, membuktikan teori, mengembangkan teori, mengumpulkan dan analisis data dalam waktu yang bersamaan. Setelah mengumpulkan data, peneliti melanjutkan proses penelitian sesuai dengan langkah-langkah pokok yang digunakan pada metode ini, yaitu menentukan masalah yang ingin diselidiki, mengumpulkan data atau informasi yang ada di lapangan, menganalisis dan menjelaskan masalah yang ditemukan serta membuat laporah hasil penelitian. Menurut(Sugiyono, 2009) teknik pengumpulan data merupakan langkah yang paling strategis dalam penelitian, karena tujuan utama dari penelitian adalah mendapatkan data. Metode pengumpulan data yang digunakan Peneliti untuk mendapatkan data dan informasi yang mendukung penyempurnaan hasil dari penelitian ini antara lain:

1. Observasi

Dikutip oleh (Satori, 2012) mengatakan bahwa, observasi adalah metode pengumpulan data yang digunakan untuk menghimpun data penelitian melalui pengamatan dan penghindar. Peneliti melakukan survey atau observasi dilakukan selama empat bulan yang dimulai pada bulan September sampai Desember 2019 pada di Kelurahan Jatijajar Kecamatan Tapos Kota Depok.

2. Wawancara

Menurut (Suwandi, 2008) ialah mengonstruksi perihal orang, kejadian, kegiatan, organisasi, perasaan, motivasi, tuntutan, dan kepedulian, merekonstruksi kebulatan-kebulatan harapan pada masa yang akan datang, memverifikasi, mengubah dan memperluas informasi dari orang lain.Pengumpulkan data dengan wawancara ini dilakukan untuk mencari data dan informasi tentang hal-hal yang dibutuhkan dalam penelitian. Wawancara ditunjukan kepada orang-orang yang berkecimpung langsung maupun tidak langsung dalam proses pengelolaan surat di Kelurahan Jatijajar Kecamatan Tapos Kota Depok.

3. Studi Pustaka

Pengumpulan data dan informasi dilakukan dengan mempelajari buku-buku yang berhubungan dengan masalah yang sedang dibahas yang diperoleh dari perpustakaan Universitas,pengumpulan data dan informasi dilakukan di Universitas Indraprasta PGRI, dan kutipan buku-buku dan browsing melalui search engineering di internet.

\section{HASIL DAN PEMBAHASAN}

Alternatif penyelesaian masalah tersebut adalah membangun sebuah sistem agar pengelolaan data surat yang masuk maupun surat keluar sehingga dapat menghasilkan laporan yang sesui dengan data dilapangan dan tidak memakan waktu yang lama lagi dalam pembuatannya, sedangkan pada SPPD diharapkan pembuatan, dan penyimpanan dapat tersimpan dengan baik, efektif dan efisien. Maka, penulis mengususlkan untuk membuat sebuah sistem informasi terkomputerisasi berbasis 
desktop java agar bisa membantu dan memudah kan bagian umum untuk melakukan pengelolaan data surat masuk, surat keluar dan SPPD.

\section{Diagram Konteks Sistem yang Berjalan}

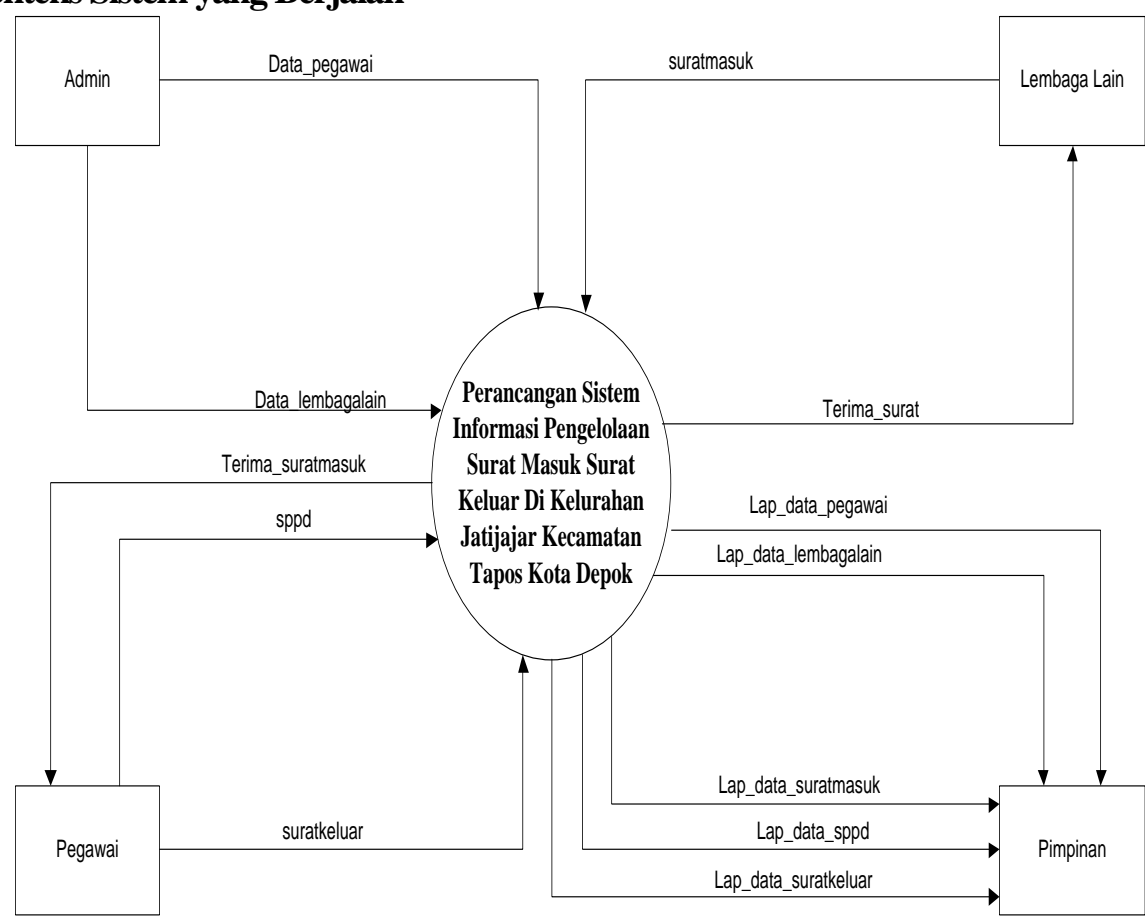

Gambar 2 Diagram Konteks yang Diberjalan

\section{Diagram Konteks Sistem yang Diusulkan}

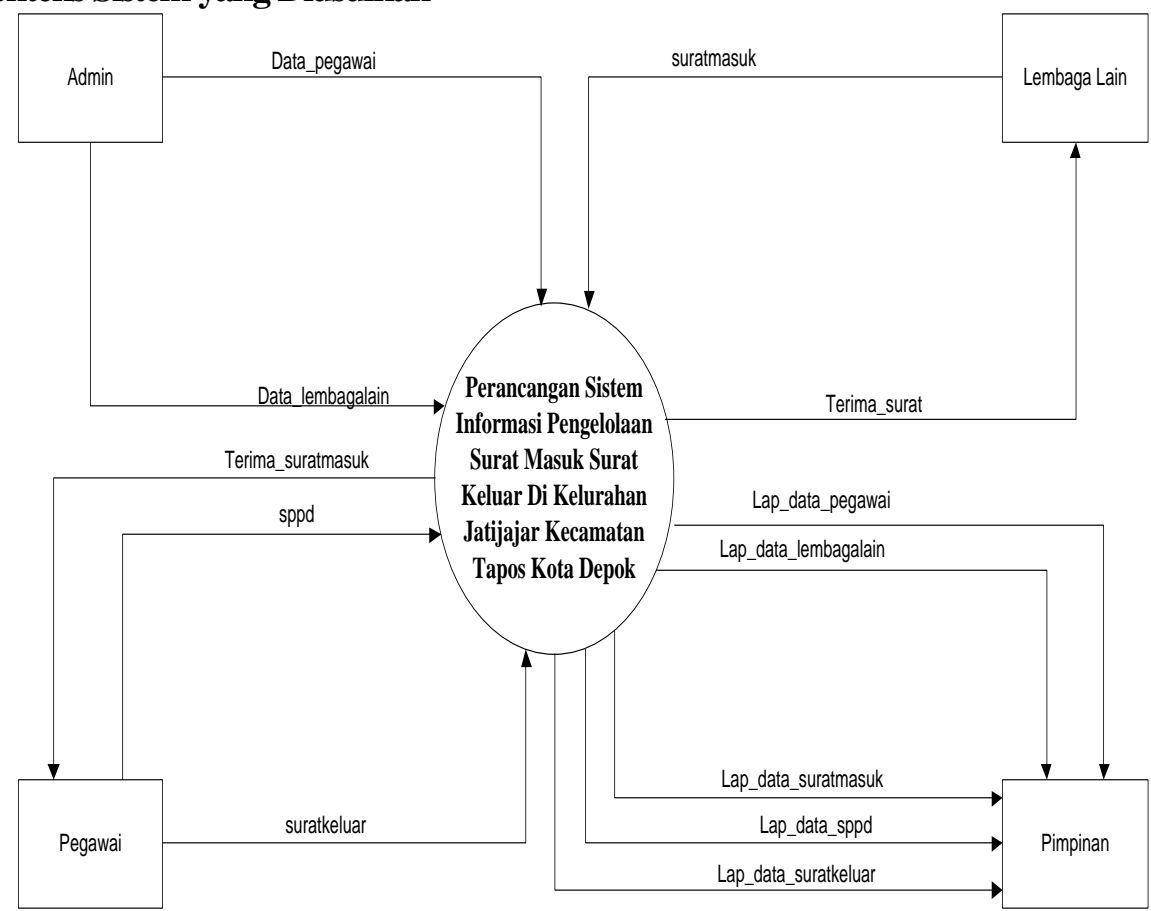

Gambar 3 Diagram Konteks yang Diusulkan

Pada diagram diatas memperlihatkan gambaran umum dari subsistem informasi pengolaan surat masuk dan keluar, karena seluruh subsistem hanya diwakili oleh satu simbol proses. Subsistem informasi surat masuk dan surat keluar berinteraksi dengan kesatuan luar atau kelompok pengguna yaitu admin, pegawai, lembaga lain dan pimpinan.Admin dapat mengakses data pegawai dan data Lembaga lain. Pegawai dapat mengentri sppd, surat keluar dan menerima data surat masuk. Lembaga lain menerima terima surat dan dapat mengentri data 
surat masuk. Untuk, pimpinan hanya menerima dan melihat seluruh laporan yang ada pada sistem informasi surat masuk dan surat keluar.

\section{Entity Relationship Diagram (ERD)}

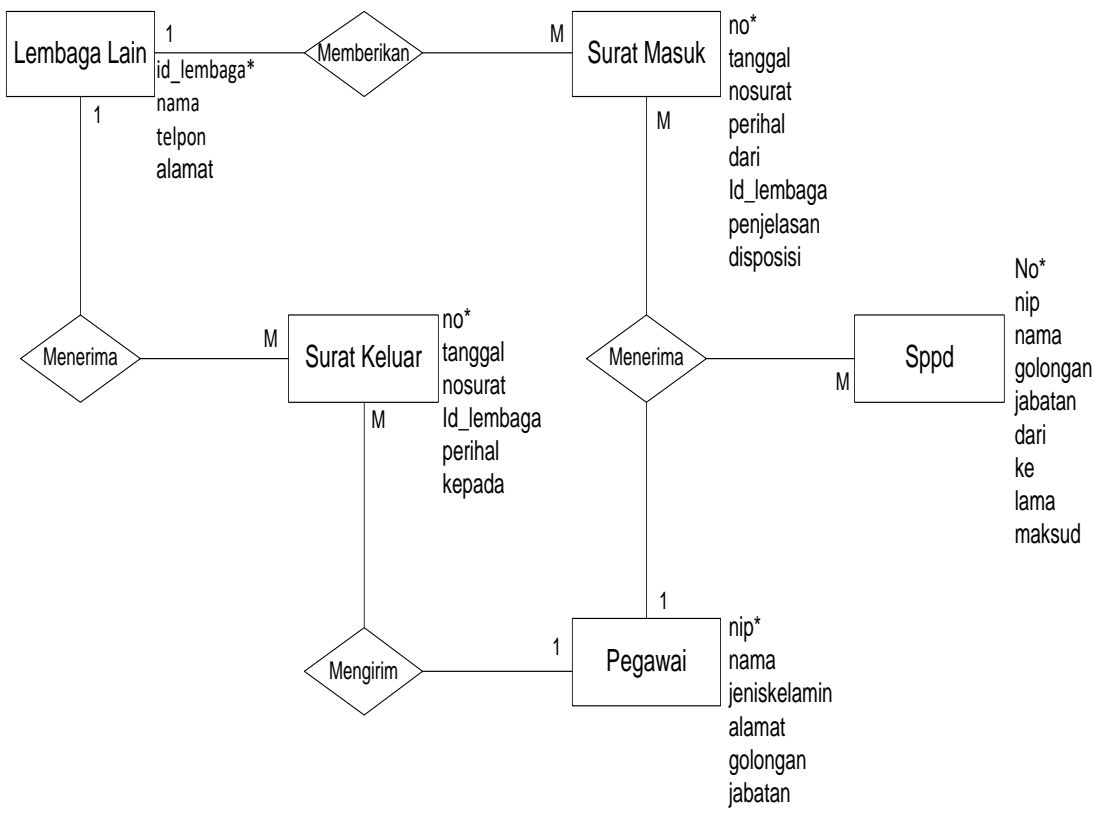

Gambar 4 Entity Relationship Diagram (ERD)

Pada gambar diatas dapat dijelaskan bahwa lembaga lain dapat memebrikan surat masuk dan menerima keluar yang dikirim pegawai. Pegawai dapat mengajukan surat keluar dan menerima surat masuk dan sppd yang diberikan lembaga lain.

\section{Rancangan Tampilan Layar}

Tampilan Menu Login

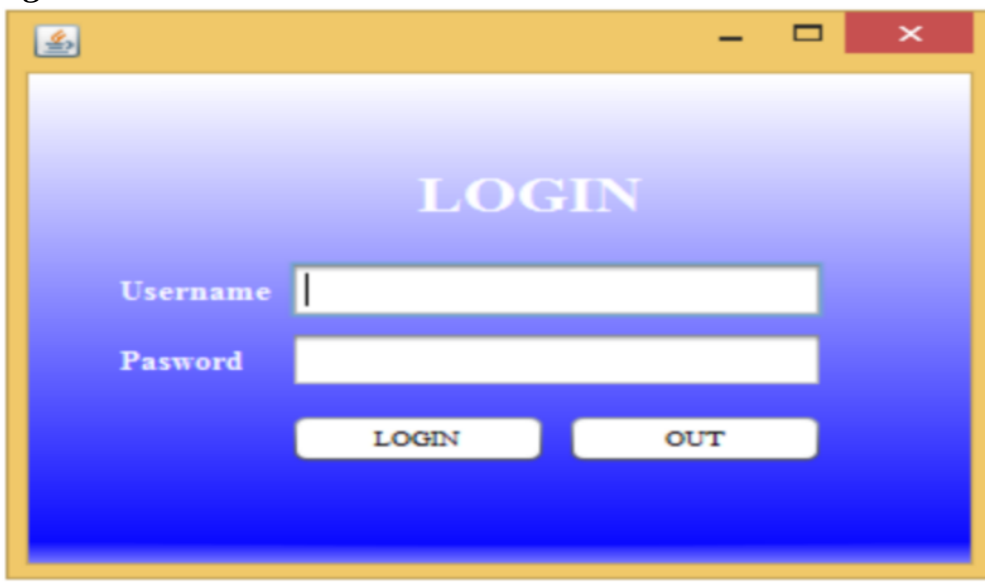

Gambar 5 Menu Login

Tampilan form login ini muncul di awal saat pengoperasian aplikasi pengelolaan surat di Kelurahan Jatijajar Kecamatan Tapos Kota Depok untuk diisi oleh admin sebagai user. Masukkan username dan password yang sesuai dengan hak akses supaya bisa mengoperasikan aplikasi pengelolaan surat di Kelurahan Jatijajar Kecamatan Tapos Kota Depok. Jika username dan password sesuai, maka akan masuk kepada tampilan Menu Utama. 


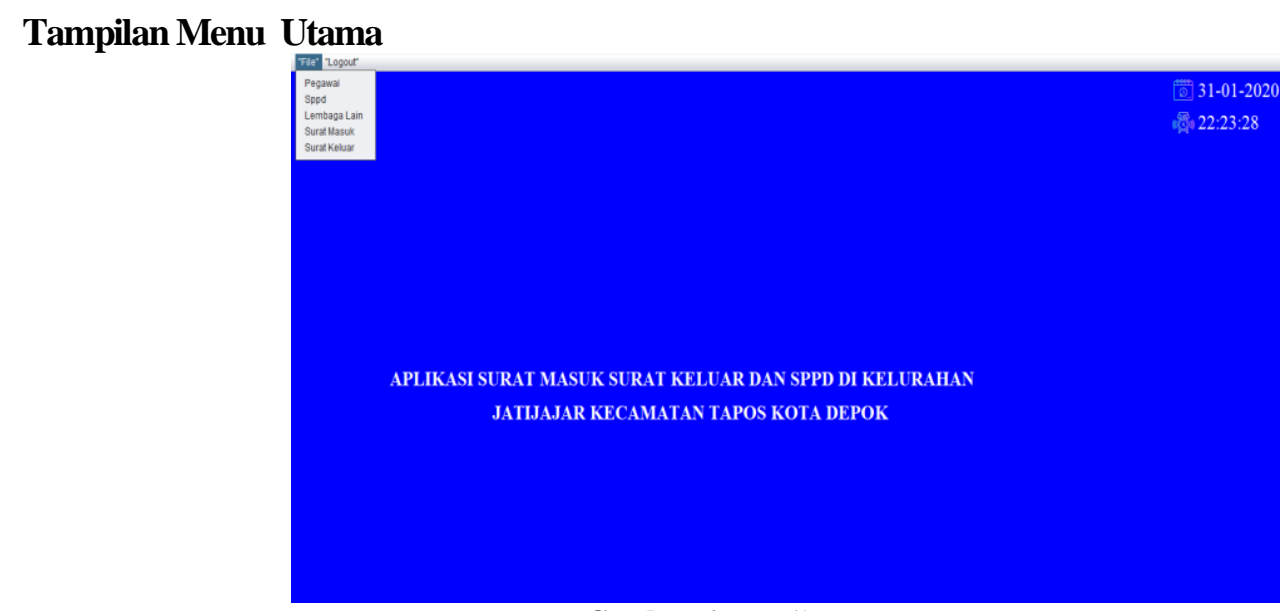

Gambar 6 Tampilan Menu Utama

Tampilan menu utama ini terdapat beberapa icon menu diantaranya file yang akan menampilkan form-form diantaranya adalah form Pegawai, form Sppd, form Lembaga Lain, form Surat masuk, form Surat Keluar dan Logout.

\section{Tampilan Form Surat Masuk}

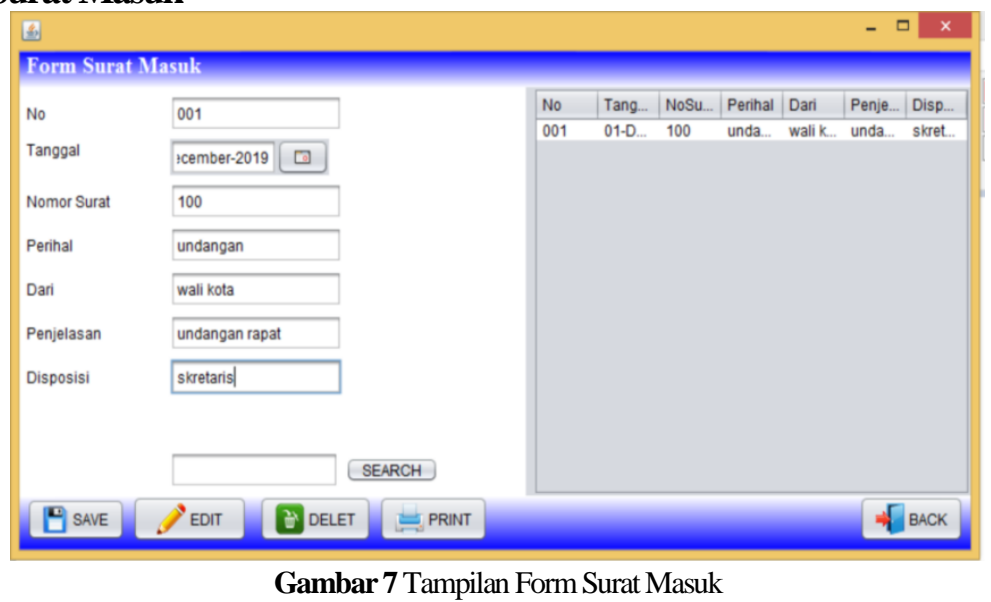

Tampilan form data surat masuk ini, user dapat melakukan penambahan data surat masuk, mengubah, dan menghapus data surat masuk. Masukkan nomor surat masuk untuk melakukan pengecekan data-data yang sudah tersimpan. Lakukan pengisian apabila akan dilakukan penambahan data dan tekan tombol (save) untuk menyimpan data, untuk memperbarui data tombol (edit), dan untuk menghapus data klik tombol (delete). Pilih tombol (back) apabila ingin menutup form data surat masuk dan kembali ke tampilan menu utama.

\section{Tampilan Laporan Surat Masuk}

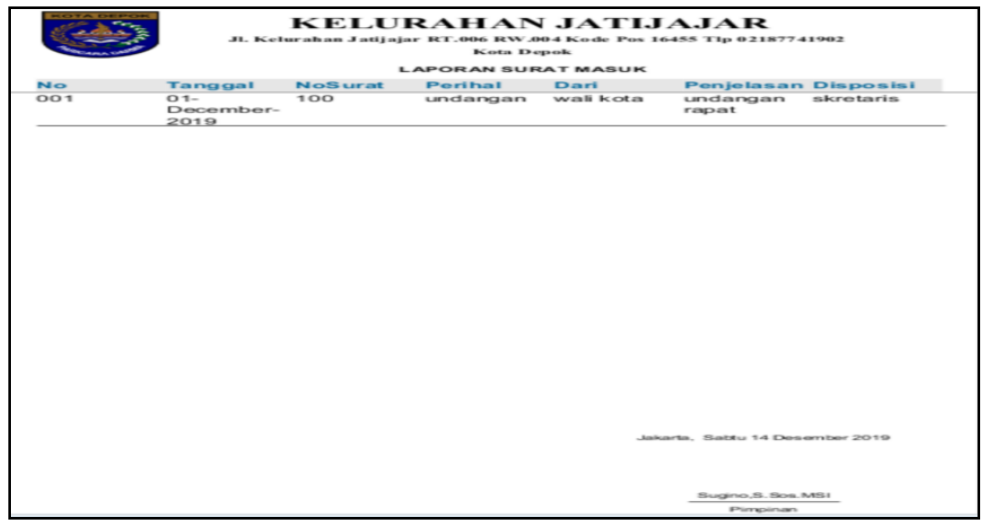

Gambar 8 Tampilan Laporan Surat Masuk 
Tampilan laporan data pegawai ini berisi data-data yang ada pada tabel pegawai. Laporan ini muncul ketika user mengklik tombol print pada tampilan from pegawai.

\section{SIMPULAN}

Dari hasil pembahasan yang telah diuraikan pada bab-bab sebelumnya, maka dapat disimpulkan bahwa dengan adanya Sistem Aplikasi Pengolahan Surat Masuk Keluar Dan Sppd Dikelurahan Jatijajar ini dapat memudahkan pihak staff keluarahan dalam mengelola surat masuk, keluar dan sppd yang ada di Kelurahan Jatijajar. Dengan menggunakan Sistem Aplikasi Pengolahan Surat Masuk Keluar Dan Sppd Dikelurahan Jatijajar ini dapat mengefisiensikan waktu serta mempermudah kinerja staff kelurahan dalam melakukan pelayanan membuat surat masuk, surat keluar, sppd serta laporan surat masuk, keluar dan sppd. Sistem Aplikasi Pengolahan Surat Masuk Keluar Dan Sppd Dikelurahan Jatijajar ini dapat meminimalisir adanya kesalahan pencatatan surat masuk, surat keluar, sppd dan laporanya, beserta pencarian dara surat yang sudah diinput. Dengan adanya Sistem Aplikasi Pengolahan Surat Masuk Keluar Dan Sppd Dikelurahan Jatijajar ini, datadata yang disimpan lebih terstruktur dan juga lebih aman.

\section{DAFTAR PUSTAKA}

Abdul, K. (2014). Pengenalan Sistem Informasi. yogyakarta: Andi Offiset.

Adhi Susano, Pujiastuti, F. A. M. (2017). PERANCANGAN APLIKASI PENGOLAHAN DATA ADMINISTRASI PENDUDUK PADA RUKUN TETANGGA WILAYAH KREO TANGERAN. Jurnal String, 2.

Ahmad Khoiril Anam, Hilda Hilaliyah, S. J. (2018). PENULISAN SURAT RESMI DI IKATAN REMAJA MASJID KELURAHAN JATILUHUR DAN JATIMEKAR KECAMATAN JATIASIH KOTA BEKASI. Jurnal PKM: Pengabdian Kepada Masyarakat, 01, 76-80.

Fatmawati, Ferryanto, C. A. (2018). Perancangan Sistem Informasi Pengolahan Data dan Pengarsipan Menggunakan Model Waterfall. Sentra Penelitian Engineering Dan Edukasi, 10.

Hassan Saputra. (2020). RANCANG BANGUN SISTEM DISTRIBUSI SURAT KABAR PADA PT JASATAMA POLAMEDIA BERBASIS WEB. Seminar Nasional Riset Dan Teknologi (SEMNAS RISTEK).

Muhamad Rizqi Aris Munandar, R. (2020). PERANCANGAN SISTEM INFORMASI PENGELOLAAN ARSIP PADA BALAI BENDUNGAN DIRJEN SDA KEMENTERIAN PUPR. Seminar Nasional Riset Dan Teknologi (SEMNAS RISTEK).

Satori, A. K. dan D. (2012). Metodologi Penelitian Kualitatif. Bandung: Alfabeta.

Sugiyono. (2009). Metode Penelitian Bisnis (Pendekatan Kuantitatif, Kualitatif, dan R\&D). Bandung: Alfabeta.

Sugiyono. (2013). Metode Penelitian Kuantitatif dan R \& D. Bnadung: Alfabeta.

Supriyati. (2012). Sistem Informasi Manajemen. Bandung: LABKAT PRESS UNIKOM.

Suwandi, B. dan. (2008). Memahami Penelitian Kualitatif. Jakarta: Rineka Cipta. 